\title{
Inducing Behavioural Change in Society Through Communication and Education in Sustainable Manufacturing
}

\author{
Ina Roeder, Wei Min Wang and Bernd Muschard
}

\begin{abstract}
The United Nations considers the mobilization of the broad public to be the essential requirement for achieving a shift towards a more sustainable development. Science can play a vital role in Education for Sustainable Development (ESD) by contributing to ESD-related research and development on the one hand, and by becoming active awareness raisers themselves in education and multiplier networks. Specifically, the use of special Learnstruments, and investment in Open Education formats among other educational tools, may pave the way for accelerated apprehension and appreciation of sustainable manufacturing topics among the greater populace.
\end{abstract}

\section{The Challenge of Creating Proper Understanding of Sustainable Manufacturing}

For all liveable future scenarios, a change of manufacturing paradigms is mandatory, not only by producers but also by customers and users. In order to realize such a behavioural change in society, it is essential to establish proper appreciation of sustainable manufacturing or in a broader perception the general concept of sustainable development. One conceptualization of a learning process holds that people have to acquire knowledge and interpret and apply it to their own personal contexts (Kolb 1984; Kirkpatrick 1996) in order to learn the lessons at hand. To assist people in undergoing this learning process, awareness of sustainable development has to be

I. Roeder $(\bowtie) \cdot$ W.M. Wang $\cdot$ B. Muschard Institute for Machine Tools and Factory Management, Technische Universität Berlin, Berlin, Germany

e-mail: ina.roeder@tu-berlin.de

(C) The Author(s) 2017

R. Stark et al. (eds.), Sustainable Manufacturing, Sustainable Production,

Life Cycle Engineering and Management, DOI 10.1007/978-3-319-48514-0_16 
raised first and foremost, and the respective knowledge has to be disseminated accordingly. A range of factors however stands in the way of that pursuit.

Firstly, the complexity attached to the concept of sustainable development impedes distinct understanding. It is often criticized as missing clear outlines and being applied inconsistently (Grunenberg and Kuckertz 2005; Michelsen 2005; Brand 2005). The predominant sustainable development model used today entails the three pillars or spheres of sustainability, which emerged with the United Nations Report "Our Common Future" by Harlem Brundtland in 1987. This model states that sustainable development is only possible when all three spheres-economic, social and environmental - are equally addressed. It was this attempt of a super-framing that successfully combined the diverse perspectives and claims that competed for leadership within the sustainability discourse in the beginning of the 1990s (Brand 2005). It was a concept that everyone could agree upon, as it was broad enough to contain contrary perspectives. The other side of the coin is that such a concept is inevitably inconsistent and therefore lacks clear outlines. From a layperson's viewpoint, this concept leads to contradictory scenarios, wherein singular measures serve to increase sustainable development and reduce it at the same time, e.g. when a turn towards environmentally friendly products and more selective consumption patterns leads to job cuts, unemployment and higher poverty rates at the production site.

Secondly, the popular spin of the term fails to mobilize people. As of the 1990s, the public debate that later turned into sustainability communication still had a clear environmental framing. Fuelled by catastrophes such as in Bhopal (1984) and Chernobyl (1986), with strong media coverage, environmentalism became a social representation, an element ultimately endowing social groups with identity (Kruse 2005). Consequences were political activism, broad framing in educational institutions, the media and the private sphere alike, and a sheer explosion of well-designed information. In short, it triggered strong reactions in civil society and central tenets which were fully embraced into people's thinking. Yet the phenomenon did not get repeated when the debate turned from environmentalism to sustainable development in the aftermath of the United Nations Conference on Environment and Development in Rio de Janeiro, 1992. In this case, social and economic concerns were added to the agenda of environmental threats (Michelsen 2005). However, this did not translate into an increase in private activism nor into the internalization of higher urgency due to heightened threats to societal welfare. On the contrary, when the concept of sustainable development as a multi-perspective issue was introduced, a strong trend of "de-dramatization" (Grunenberg and Kuckertz 2005) set in, which persistently increased in the following decade. The challenges and possible measures were communicated and regarded as less immediate and rather long-term in their effects, which resulted in lower level short-term mobilization.

Consequently, despite society's increasing familiarity with the sustainability terminology, appreciation of the overall concept and awareness of its concrete meaning in everyday life remain low. In Germany, for instance, 15 years of intensive efforts to communicate sustainability through federal institutions and 


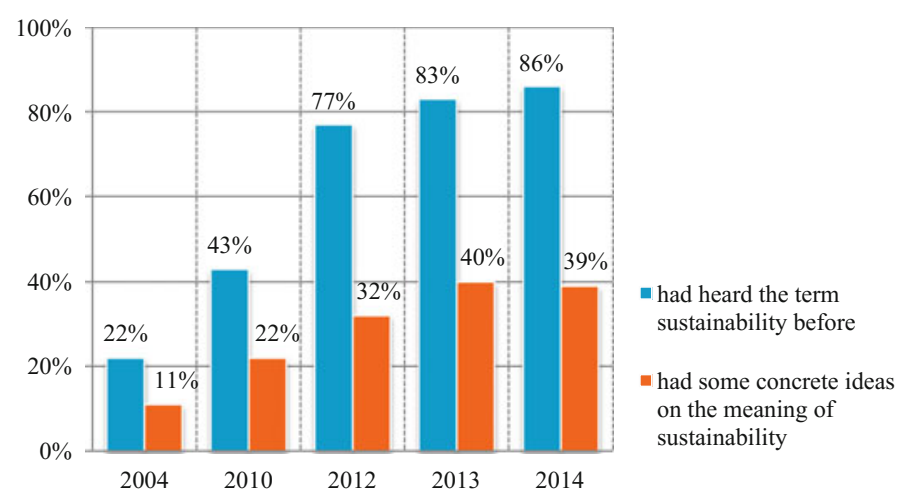

Fig. 1 Average Germans' acquaintance with the term sustainability over time (Roeder et al. 2015)

broad media coverage endured with some effect on people's awareness of the topic as shown in Fig. 1 (Roeder et al. 2015). Still, in 2014 only $39 \%$ of the people had some concrete ideas on the meaning of sustainability and less than about $4 \%$ associated it with future-aware behaviour. As these facts apply to Germany, a nation known to have an elaborated educational system and easy universal access to information, the direness of the information campaign can be expected to apply even more seriously to people from parts of the world with little access to information and a low level of basic education.

With the sustainability challenge becoming increasingly urgent, awareness training continues to be a central task of all activities aiming at sustainable development. This holds especially true for the field of sustainable manufacturing, which is so far widely neglected in public discourse, in spite of its great impact on all areas of human living. To be sure, the educational frameworks for school education have been recently rewritten in Germany to incorporate sustainable development into the curricula as a basic principle as well as a specific learning objective. Nevertheless, the sustainability impact of manufacturing is hardly considered (Roeder et al. 2016). However, considering the German example described before, classic measures seem to have failed so far in communicating the complexity of sustainable development, and especially sustainable manufacturing, to people with little previous knowledge. Just as sustainable development can only be achieved when activating the majority of populace, this majority can only be won over when stakeholders from diverse fields of sustainable manufacturing are activated to join in and strengthen change in society.

This chapter is meant as a guide to support the planning of knowledge dissemination measures in multi-disciplinary research projects. A general approach for sustainability communication is introduced to highlight integral aspects in the planning process. Furthermore, present gaps regarding mediation of knowledge about sustainable manufacturing are identified. By providing best-practice examples, it will be demonstrated how specific challenges can be met. A central aspect addressed in this context is Education for Sustainable Development (ESD), which 
aims at teaching competencies as a combination of certain skills and knowledge that enable the learner to understand, judge and act according to the sustainability maxim (Wals 2015). Education for Sustainable Manufacturing (ESM) in this regard is seen as a partial aspect of ESD with concrete focus on industrial aspects. The importance of education is also stressed by the Organisation for Economic Co-operation and Development (OECD) and the United Nations (UN), as, both organizations agree on education being the main resource for societal change towards sustainable decision-making (Bormann 2005). It is further argued that science, in its unique position as a neutral and reliable source of knowledge, should figure into the equation as a key stakeholder in spreading the word of sustainable manufacturing.

\section{General Approach for Science-to-Public Sustainability Communication}

As sustainability communication intends to reach a great number of people, it can be considered as a form of mass communication. Following the fundamental model of mass communication developed by Lasswell (1948), every action in this context should be designed by asking the "five Ws": who says what, in what way, to whom, and with what effect? Although widely criticized for its ignorance of the receivers' active role in influencing the communication by giving feedback to the sender of the message, those "five Ws" represent, to this day, the major fields of mass communication science. Answering these questions in the context of sustainability communication from a scientific point of view, forms the boundary conditions for the respective communication framework.

\section{"Who"-The Communicator}

The role of communicators in their domain and their intended communication goal, imparts a strong influence on the message, the channels and the target groups. This matter of who does the communicating is also key to where the problem lies. Communicator credibility depends on status and expertise on the one hand and on affectionately ascribed trustworthiness on the other. For the US it has been shown that professors are ascribed both, expertise and trustworthiness (Fiske and Dupree 2014). This gives them an excellent initial position as communicators for people will tend to believe them and agree with their opinions. Contrarily, scientists, researchers and engineers are seen as experts but tend to be allocated less trust, which reduces their credibility ascribed by the broad public. However, people's trust in someone changes significantly with this person's position in relation to the position of those who judge. This means, while the majority may not ascribe great trustworthiness to scientists, researchers and engineers, the result is different when asking sections of society that have certain aspects in common with those communicators, e.g. a high educational level. Also the ascribed trustworthiness is 
expected to increase when those scientific communicators show concern for humanity and the environment; both being the case for manufacturing-oriented sustainability communication.

For people transmitting sustainability knowledge, such as teachers, the greatest capital is knowledge. These educators need to be sceptical towards new information which they are persuaded to implement in their teaching activities by non-official bodies, and, furthermore, be concerned, among other things, about the correctness of the information and the underlying interests of the persuader. This locates them near science communicators, making them a convenient target group for science communication. When it comes to decision-makers (e.g. in politics), the reputation of an information provider who is well-established in a certain field of expertise, offers opportunities with influential stakeholders and increases the chances of being heard. This is where publically funded science has an invaluable advantage. It is considered neutral and exact in the highly competitive arena of sustainable manufacturing.

As a communicator, science has a vital position in passing on knowledge. Hence, it has a triple role to play in (1) generating communicable knowledge about sustainable manufacturing, (2) developing new scientifically sound dissemination techniques and acting as a communicator with great credibility, and (3) promoting knowledge dissemination and awareness raising for sustainable manufacturing. Consequently, communication and teaching aspects should be considered in every research project within the field, right from the very planning phase onwards.

\section{"What"-The Message}

The overall message of sustainable development is clear-we need to live in such a way that future generations can have an average standard of living which is at very least equal to the one we have today. The message of sustainable manufacturing is even more narrowly defined, insofar as stating that dynamics of global competition and cooperation can be used for lending wings to processes of innovation and mediation towards the goal of global sustainability. Clear as those definitions might appear in this abstract form, thorough understanding of the concepts requires profound understanding and perspectives that are currently lacking in the narration of the public discourse and thus hardly intuitive. To enable knowledge of sustainable development and manufacturing, and to facilitate that message getting communicated in a comprehensive way, it has to be applied to the context of the target groups, e.g. by relating it to monetary values for industrial producers or strategic advice in daily life situations for consumers. As shown in this book, a multitude of examples demonstrate how technological, social and economic innovations can be integrated with each other to contribute to sustainable development by means of saving resources, increasing the living standard throughout the world without increasing consumption, and developing business models that are based on functionality rather than on personal ownership. Particularly with regards to communication to the broad populace, a crucial aspect of the message is to raise awareness about the complex nature of sustainability. The goal should be to create a differentiated understanding of the term and hence to allow for sophisticated decision-making in daily life. 


\section{"To Whom"-The Target Group}

Considering the communication goal of changing people's behaviour, and the findings on credibility described above, it becomes obvious that it is insufficient to simply view the broad public as one homogeneous target group. Moreover, experience from former sustainability communication measures shows us that mass coverage can only play a supportive role in the whole process (Roeder et al. 2015). With respect to the variety of potential recipients and communication goals, no panacea exists. Hence, addressing multipliers becomes an integral part of mediating knowledge to large numbers of diverse recipients. Multipliers can be defined as persons who have the ability to influence the opinion, the behaviour or the actions of a social group by virtue of the authority assigned e.g. by their social status or professional expertise. Their relevance results from their hybrid nature, as they constitute just as much the target group as they do the role of communicator. Multipliers can be, for example, teachers, trainers or any other people in positions who communicate with a great number of citizenry in their day-to-day work. They can also be decision-makers who influence a lot of people's behaviour by deciding on the choices they get to make, e.g. product designers or politicians. Lucky for scientifically-based sustainability communication, those are the very target groups who are likely to ascribe publicly funded science communicators high credibility, as argued above.

By involving multipliers as a mediating party, a simplified model of sustainability communication has been introduced that consists of three sets of communicators and target groups respectively. All three parties together represent the communication network of science-to-public sustainability communication (Fig. 2).

Each party has to be understood as a communication partner who possesses valuable information on sustainable development and power to influence its dissemination into society. For instance, teachers can give information on what materials or tools they require for teaching sustainability. Decision-makers have insights into the constraints that influence people's behaviour, which often go unnoticed. The

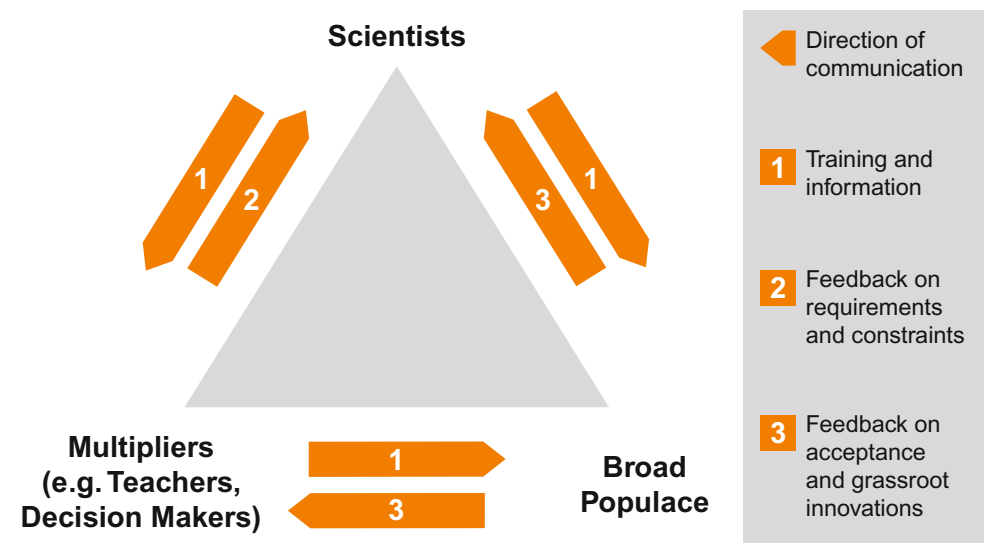

Fig. 2 Simplified communication model for dissemination of sustainability knowledge from a scientific stakeholder perspective 
broad populace may have information about the acceptance of sustainability measures as well as about grassroots innovations and movements.

Viewing education as a core vehicle for transferring sustainability knowledge into society allows for a more differentiated view of the target groups. While the OECD and the UN consider education at all levels of formal and non-formal education, teaching a holistic understanding of sustainable manufacturing requires more specific target groups. Although it is useful if general ideas of sustainable development are taught from early childhood onwards in conjunction with a uniform set of values, the integration of industrial aspects such as technology, production planning and business models, should wait until the learners' cognitive ability has matured enough to process such complexity.

The human brain develops rapidly up to the age of about twelve. At the age of 13, further increase in memory performance is usually slow and marginal (Ahnert 2014). The ability of hypothetical and scientific thinking emerges, enabling the young learner to verify hypothesizes by using logic. The cognitive ability developed by adolescence enables the students to rapidly extend their semantic networks from that point on (Ahnert 2014). Well-developed semantic networks are fundamental to complex thinking, such as needed for understanding the workings of sustainable manufacturing challenges and solutions. It can be therefore clearly recommended to concentrate on target groups from the age of around 13 onwards when teaching complex aspects of sustainable manufacturing. Of course, it helps by

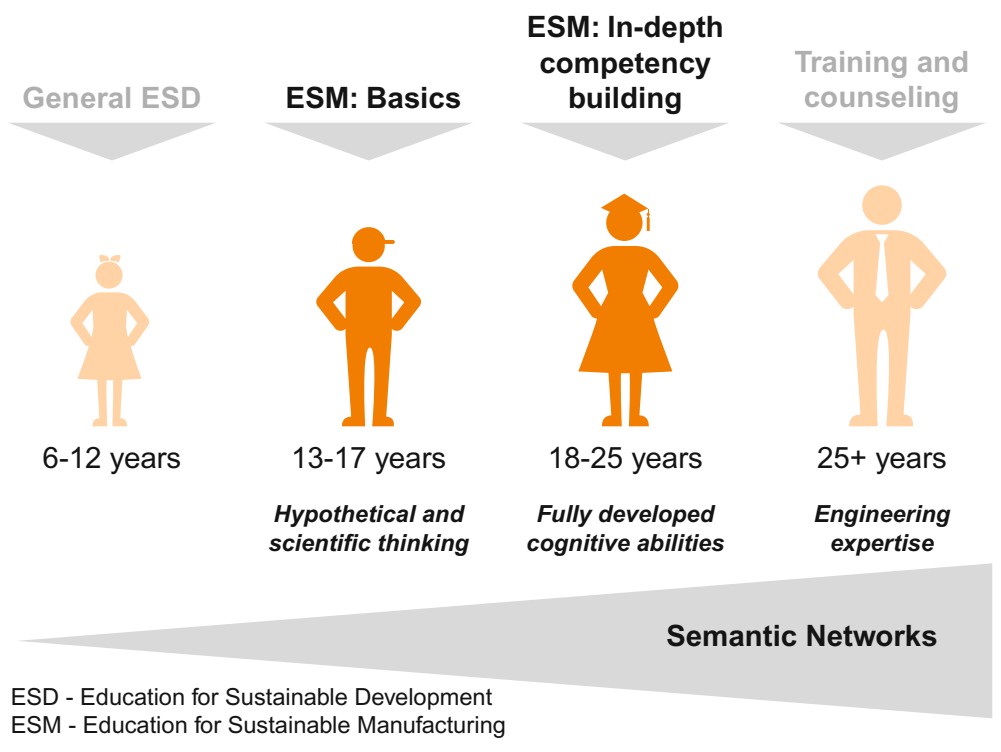

Fig. 3 Levels of education for manufacturing-related sustainable development 
all means if the students are already familiar with more general aspects of sustainable development and science by that time, as demonstrated in Fig. 3.

Teaching sustainable manufacturing at the high school level again lays the foundation for easy integration of correlating assumptions into higher education. Still, the main focus of engineering and engineering economics education lies in classic paradigms such as profit maximization. Sustainability aspects are inadequately represented despite the dire need to sensitize future manufacturing experts to their responsibility as decision-makers and teach them how to plan and implement sustainable manufacturing. In summary, ESM, although generally building upon ESD, needs to target high school students in order to prepare them for further training as engineering or engineering economics students in higher education so to pave the way for new, sustainability-oriented paradigms in manufacturing. Also targeting the youth in general means targeting the next generation of consumers, whose product choices make them direct stakeholders of sustainable manufacturing if they choose to invest in sustainable products and sustainable production. Through the same mechanism they can also have indirect effects as a pressure group on enterprises that still follow unsustainable manufacturing strategies.

\section{"In What Way"-The Channel}

Target group orientation is the core of successful communication. The channels that are used are therefore as manifold as the target groups to be communicated with. Those channels can be direct or indirect, depending on the assignment of the target group as shown in Fig. 4. Apart from research-based communication such as interviews in direct communication and survey sheets in indirect communication, the focus of direct communication with multipliers is on training and through active participation on the part of the respective stakeholder networks. The broad populace can best be reached by offering exciting events with a high entertainment factor or even public educational projects. Indirect communication can work by offering specific training materials such as extended teacher manuals complete with teaching materials or materials for qualifying teachers as "Teachers of ESD" as a labelled skill enhancement, for example. Training materials and appropriate manuals for skill-enhancement likewise play a major role in the indirect communication with multiplying decision-makers, especially from industry. Broad populace is thus reached indirectly through teaching or through informational materials offered by the trained multipliers, and also through a variety of activities such as exhibitions or competitions.

Useful communication formats and tools differ greatly among the target groups. It is necessary for effective communication to choose carefully the channels that are to be used. The channels described above are meant to be supplementary to the well-established channels of scientific and journalistic media production such as articles or print media.

\section{"With What Effect"-The Result}

Just as the impact of every communication activity should be measured and every new product should be tested, the impact of innovative ESD activities needs to be monitored in order to identify undesirable effects or outright ineffectiveness. The 


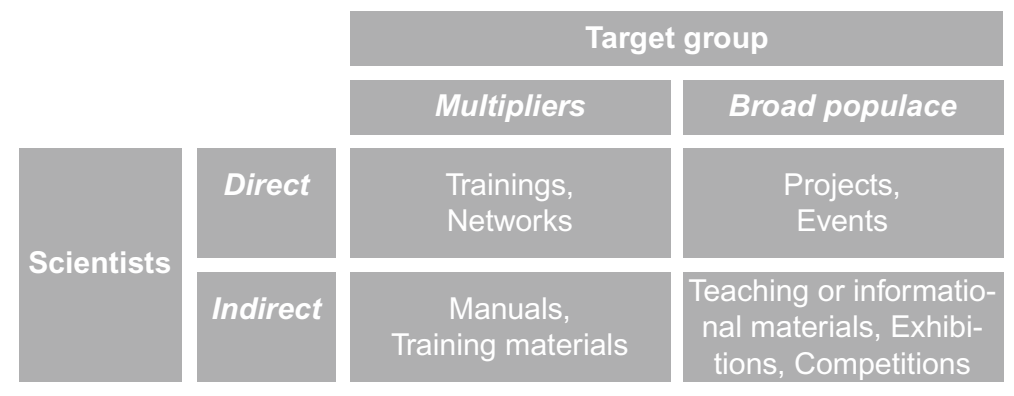

Fig. 4 Exemplary ESD communication from a scientific stakeholder perspective

outcome of studies on knowledge gained and attitudinal or behavioural change can usually not be expected to represent a fixed reality. It lies within the nature of social sciences that there are as many social realities for a surveyed person as there are social or psychological circumstances which this person experiences. The situation becomes even more complex when the participants are children whose semantic webs and other cognitional modes are not yet fully established (cf. Ahnert 2014). In that vein, planning research designs for such target groups proves to be challenging. Pre-tests of the design are thus absolutely necessary in this context. Especially if a research group's main focus lies in the technological field - as to be expected when it comes to sustainable manufacturing-social scientific expertise needs to be integrated in order to confront this challenge. However, a great number of cases and careful research design can provide valid data on knowledge, attitudinal and behavioural development subsequent to a treatment e.g. an ESD measure. This data is fundamental to developing effective ESD solutions that are capable of contributing to the societal change of paradigms towards sustainable development.

\section{Present Gaps and Best Practice Solution Examples}

This section presents exemplary gaps in ESD and ESM which were identified in the course of an interdisciplinary research project on sustainable manufacturing. In the following paragraphs, some of these gaps are introduced in context, along with best practice solutions.

\subsection{Sustainable Manufacturing in High School Education}

A special focus of the Agenda 21, the UN development program for the 21st century, lies with children and teenagers. In Germany, the programs " 21 " and "Transfer-21" have been set up as local forms of the Agenda 21 from 1999-2008 in 
order to improve sustainability teaching at German schools, with moderate success (Roeder et al. 2015). While educational frameworks have been rewritten in Germany in order to integrate sustainable development into formal education, a survey with above-average students in 2014 showed that only about $50 \%$ had any future-oriented associations with the term.

In-depth sample interviews with high school teachers showed that they did not feel competent to teach sustainable development, let alone sustainable manufacturing (Roeder et al. 2016). They felt a lack of fundamental appreciation of the topic of sustainable development and furthermore lacked the teaching materials that would help them to overcome their knowledge deficiency in class. That this notion is a common one among teachers becomes apparent in a study with educators from schools that are implementing ESD programs under a local German program in 2015. Although all participants are already involved in ESD activities and have been offered qualification courses, $44 \%$ say it is difficult to develop the necessary competencies for teaching ESD, and $51 \%$ claim, moreover, that it is difficult to find adequate teaching materials.

\subsubsection{Open Educational Resources}

The challenge of lacking adequate teaching materials for a fast developing field with multiple perspectives could be met by solutions from the open knowledge movement. That is, high expectations for educating the populace worldwide have been raised by the concept of so-called Open Educational Resources (OER). The Paris Declaration of the UNESCO 2012 World Open Educational Resources Congress defines OER as "any type of educational materials in the public domain, or released with an open license, that allows users to legally and freely use, copy, adapt, and re-share".

OER are dynamic. They can be quickly adapted and shared since they are supposed to be produced in an open format and shared online. They also allow for a wider variety of cases and examples than can be covered by a textbook alone. OER thereby encourage teachers to tailor their teaching units according to their students' interests or current debates. This is where topics such as sustainable manufacturing, which are widely neglected in education so far, can still be brought to teachers' attention.

Sustainable development is mainly scheduled for the 9th and 10th grade at German high schools (Roeder et al. 2016). A search for German OER on sustainable development linked with topics of technology or industry for this target group in 2015 brought 29 results of which 18 also included at least one working sheet to use in class. Most of them had been developed for the subjects of geography, social sciences, biology, politics, religion/ethics, and economics. An analysis using the LORI ${ }^{1}$ method, assessing the items in seven categories on a 5-point scale with 5 being the maximum score, showed an average (arithmetic) score of 3.6. Although some

\footnotetext{
${ }^{1}$ Learning Object Review Instrument by Leacock and Nesbit (2007).
} 


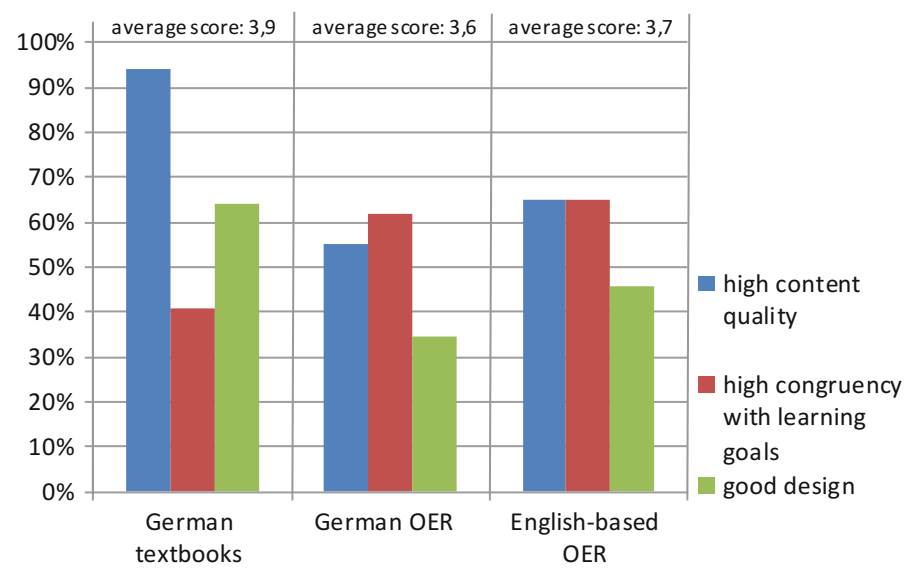

Fig. 5 Comparison of teaching materials assessed with the LORI method

resources, especially those from official bodies, scored very high, only $55 \%$ had good (4) or very good (5) results at the assessment of content quality as shown in Fig. 5. Another weak spot has been identified to be design: Only 10 out of 29 items scored good to very good. $62 \%$ had high or very high congruency with the defined learning goals and $63 \%$ included motivational elements such as varying assessment types. Generally the OER scored lower than the sustainability sections of geography text books for the same target group; those having an average (arithmetic) score of 3,9.

The exemplary international search for English OER on sustainability and technology or sustainability and industry for the same target group ( $n=48,23$ including working sheets, 131 identified items total) revealed the USA and Canada to be the main producers of OER on the topic for this specific target group. However, there are also free English teaching materials accessible by providers from the UK, Australia, Norway, and France among others. The LORI assessment of 48 items that met the requirements of topic and target group best showed a slightly higher score of the English OER than of those produced in German language, the average (arithmetic) score of the international OER being 3,7. $65 \%$ of the English-based OER were assessed to have good or very good content quality and congruency with the learning goals. 22 out of 48 assessed items scored good to very good with regard to design.

Apart from often poor didactic design, the connection to core sustainable manufacturing topics were only marginal in most cases. This is a gap that needs to be filled if the topic stands a chance of getting incorporated into high school curricula. Since content quality is one of the weak spots, science has a clear advantage as a producer of up-to-date and technically sound content. Critical in that pursuit is that the research teams intending to produce OER as a tool for raising awareness for sustainability must be multidisciplinary and bring together technical and didactic expertise. An example of this has been done within the Collaborative Research Centre (CRC) 1026 "Sustainable Manufacturing-Shaping Global Value 
Creation" (Roeder et al. 2016). When developing and producing their teaching unit on "Sustainable Manufacturing," the scientists followed a 3-step action plan covering content definition (1); didactic structuring (2); and material production (3).

\section{Content Definition}

Resource consumption in manufacturing is the central theme of the OER developed by CRC 1026, addressing matters of human, natural and economic resources. In a first teaching unit, general information on sustainable development built up to the connection with manufacturing issues, so that, for example, the three pillars of sustainability were explained from a manufacturing perspective. This was then exemplified by a second unit discussing bicycle production in the context of more specific sustainability issues within global value creation, such as producing in low-wage countries, distributed production and $\mathrm{CO}_{2}$ emissions. A third unit addressed Maintenance, Repair and Overhaul as clearly technical topics of sustainable manufacturing, also addressing, for example, planned obsolescence.

\section{Didactic Structuring}

In the interest of implementing the educational frameworks with the ultimate criteria of introducing teacher materials, nationwide educational programs were analysed for their explicit reference to sustainable manufacturing. It became clear that sustainable development is mostly set to become a fixed part of the 9th and 10th grade curricula and for all geography classes in nearly all federal states. To that end, the content was defined according to these frameworks' competencies and learning goals, such as "cosmopolitan acquisition of knowledge, including multiple perspectives" which was met, for example, by means of a role-playing exercise in which students take on various roles of producers, workers and customers from different geographical and cultural backgrounds. The learning goals of each exercise and their links to the educational framework, along with further didactic information, were all made explicit in an accompanying teacher's guide.

Each unit was structured following a reduced learning spiral oriented at Mattes (2011). To sum up, the procedure starts with teacher-oriented learning, requiring increasing self-study and group study as the lessons proceed, and finally ending with teacher-led concluding elements which follow up on individual learning results. Obviously the content must be general in the beginning, using everyday experiences of the target group as the starting point. It gets more specific as the lesson proceeds. At the end of the lesson, exercises are designed to ask students to transfer the acquired principles to other fields.

Since the material is supposed to be usable at different proficiency levels, a focus has been set on internal differentiation. Hence, exercises are set in three levels of difficulty.

\section{Material Production}

The best content will be ignored by teachers and students alike if the design is not appealing. The CRC 1026 invested in a professional designer for layout and graphics. OER are free of charge and free to adapt. In using OER, it is however of 
utmost importance either only to use graphics that are offered under a global commons license, or to produce them explicitly as such. A challenge when creating OER is adaptability. A publishing licence allowing for adaption is no benefit if the format and design of the materials offered are themselves not adaptable. It is thus paramount that the designer does his/her work with software that most teachers or even students have access to. In that vein, CRC 1026 decided to do its layout in Microsoft Powerpoint in order to foster easy exchange of graphics or text blocks.

\subsection{Sustainable Manufacturing in Higher and Vocational Education}

Promoting excellence in engineering has emerged as a strategic goal on the part of industry, society and nations in pursuit of improving living standards. The European Technology Platform for Future Manufacturing Technologies (Manufuture) highlighted the role of engineering education explicitly as a key driver in achieving this goal (Manufuture 2006). Chryssolouri recommends "manufacturing education should follow new approaches so as to prepare industry for the next-generation innovation and the support of its growth" (Chryssolouris 2005).

Innovative sustainable manufacturing offers a vehicle for coping with the challenge of sustainability. New training and education activities within organizations comprise the lever for achieving higher education in this area. For structuring an engineering design course with respect to teaching aspects of sustainability, Pappa et al. (2013) took Bloom's taxonomy of the cognitive domain as a basis. Yet the development of an approach in engineering wherein instruments are used to convey aspects of sustainable manufacturing with regards to the affective and psychomotor domains, was however hardly discussed.

\subsubsection{Learning Through the Support of Technology-Learnstruments}

Great potential for increasing the awareness and the learning and teaching productivity on sustainable manufacturing topics is seen in addressing the matters of technical content and the learner's feeling, values or psychomotor skills at the same time. Such instruments for learning could be found in so-called Learnstruments.

Learnstruments are production technologic objects both tangible and intangible, automatically demonstrating their functionality to the user. They aim at increasing the learning and teaching productivity and expanding the awareness of the environmental, economic and social perspective of sustainability. By their application, Learnstruments enhance organizations' human, structural and relational capital through higher skills and knowledge, structure and collaboration.

The neologism Learnstrument consists of the words learning and instrument. Learnstruments support the learning process by providing adequate learning goals to the user. Instruments in this sense are considered as objects supporting the user 
effectively and efficiently in achieving the learning goals. Furthermore, learning processes can be designed in a new fashion, focusing on sustainability to shape people's understanding of this important topic during training and learning.

They address cognitive, affective and psychomotor learning goals and strive towards the fulfilment of high level learning goals. Enabled by new and existing information and communication technology, Learnstruments allow the determination of the user's cognitive learning level and provide adequate learning goals towards the fulfilment of creation. Repetition strengthens the user's psychomotor ability for adaptation of human skills to execute manufacturing tasks.

The concept of Learnstruments is introduced and illustrated with two prototypical implementations.

\subsubsection{CubeFactory}

The CubeFactory is a Learnstrument addressing the understanding of a closed loop material cycle of polymers by an application-oriented mediation process. This mini-factory constitutes self-sustaining learning and production equipment which contain the main components involved in value creation, such as material processing, energy supply, manufacturing tools and tools for knowledge transfer. Based on the learning cycle of Kolb (1984), the CubeFactory considers aspects of perception and processing continua designed to increase learning productivity. The user is methodically supported in knowledge creation by the elements of concrete experience, reflective observation, abstract conceptualization and active experimentation. An open source 3D printer is the main value creation tool. The additive manufacturing process is regarded as sustainable since it places material exactly where it is needed to build up the workpiece. Unlike subtractive processes such as turning, milling, drilling, virtually no waste or by-products are generated in the whole process.

The so-called Home Recycling Device (HRD) serves as a material supplier for $3 \mathrm{D}$ printer consumables and demonstrates the value and potential of plastic recycling. A mechanical knife-shredder granulates thermoplastic waste that is further processed into an electrically heated screw extruder. This can turn a non-valuable object like thermoplastic domestic waste, into a valuable product like 3D printer filament. "Comparing the cost of $100 \mathrm{~kg}$ of sorted plastic waste $(\$ 1.00)$ with $1 \mathrm{~kg}$ of 3D printer ABS-filament (\$25), an up lift ratio of 2500:1 is realized" (Muschard and Seliger 2015; Reeves 2012). Through the application of the HRD, the user learns that local processing of raw materials can shorten or even eliminate distribution channels, can reduce the volume of waste, can save on $\mathrm{CO}_{2}$ emissions, and at the same time ultimately make the production of goods more cost effective. An important lesson in the mediation of sustainability is that energy cannot be produced, but only converted. In a sustainable manner, it applies to abdicating non-renewable resources and to making renewable resources available.

For those purposes, the CubeFactory contains a self-sufficient energy supply system formed by solar modules, rechargeable batteries and a battery management 
system. The knowledge transfer device is a learning environment implemented in a touchscreen tablet computer, supporting the user in exploiting the potential of the mini-factory. It assists the user in comprehending the CubeFactory's manner and in carrying out learning tasks in a simple and intuitive way.

To address a broad spectrum of users, to arouse curiosity and to motivate the learner, the CubeFactory is designed taking differences in knowledge, skills, age, disability or technological diversity into account (Fig. 6).

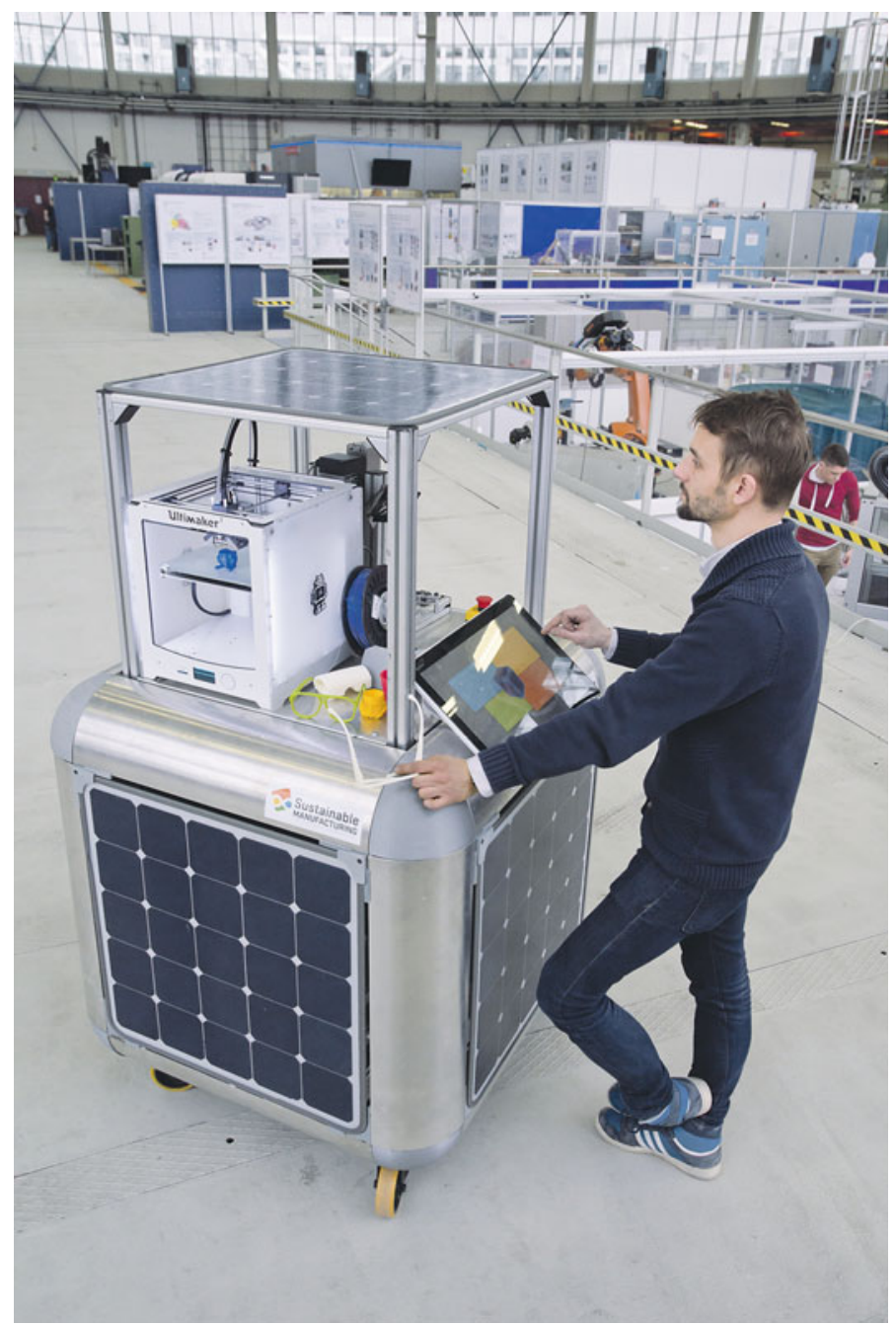

Fig. 6 CubeFactory: mobile, self-sufficient mini-factory 


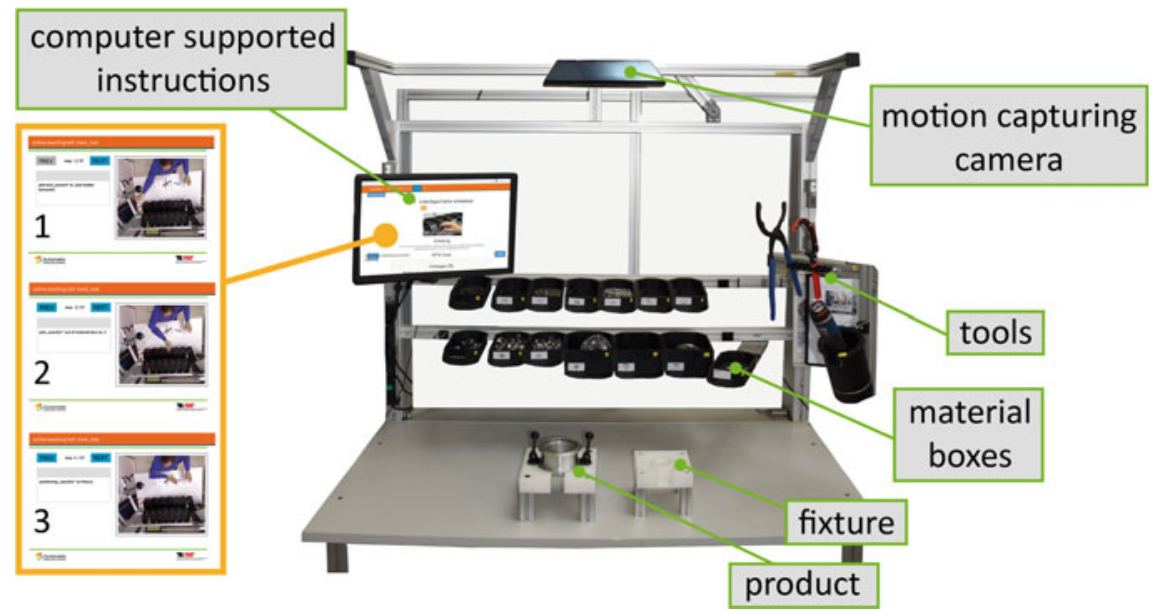

Fig. 7 Smart Assembly Workplace: assembly sequence of bicycle e-hubs is automatically transmitted to the user

\subsubsection{Smart Assembly Workplace}

The Smart Assembly Workplace (SAW), shown in Fig. 7, is a learning workplace for manual (dis-)assembly tasks with the example of bicycle e-hubs. It equips the worker with the tools and know-how needed to improve and plan such a workplace on their own. The learning-path is structured in initial learning and consecutive in-depth e-learning. It consists of fixtures, material boxes, tool holders and a camera to be affixed at the workplace.

During initial learning, users less experienced in assembly obtain a basic overview of the assembly sequence. The main requirement for this is to give the user immediate feedback referring to her/his current constitution and actions. By means of a marker-less motion-capturing software (Krüger and Nguyen 2015), the hands of the user are tracked by the system. Whenever the learner enters a so-called event-zone, an internal time stamp is logged and the assembly description automatically reveals the next assembly step on the display. In case of a mistaken action, a message is displayed to the user.

When the user enters, for example, the nuts-bunker with her/his hand, it can be assumed that at least one nut has been picked. On the basis of the time spent, conclusions with respect to the current work performance or level of learning of the user can be drawn. As soon as the worker's performance reaches the target time according to Methods-Time Measurement (MTM), the respective MTM-code is displayed to the user via the computer-supported instruction. It is utilised for the purposes of analysis and planning of working systems. By this representation, the user implicitly learns about the composition and meaning of the respective code.

The learner can use an e-learning module facilitating MTM knowledge in a self-explanatory way. The module consists of descriptions, hints and 
recommendations about the usage of MTM with the example of the bicycle e-hub. In a final stage, generic suggestions for improvement are displayed to the learner. These improvements are dedicated to assisting in the process of creating ideas for improvements in the learner's workplace (McFarland et al. 2013).

Although learning and understanding are intrinsic processes, this happens mostly in the setting of an interaction between the learner and the environment. Intelligently designed technologies and artefacts can assist the human in her/his learning process, and help to enhance teaching and learning productivity. The increasing digitization of manufacturing opens up new opportunities for knowledge transfer, in which the teacher and the learner no longer need be present at the same location.

The SAW replicates the production technology laboratory of the Vietnamese-German-University in Ho Chi Minh City, Vietnam. An assembly description, recorded at the German SAW, was transferred to the Vietnamese one. It was shown that the students in Vietnam-having scant knowledge about assembly -were able to assemble e-hubs with the help of this description. An expert was not required to be present in Vietnam to that end at all.

\subsection{Facilitating Appreciation of Sustainability Aspects Through Gamification}

As described above, the topic of sustainability is rather complex and it therefore takes time to supply an interested person with the necessary knowledge. In the context of the general public, the interest in picking up information without being forced to (by work, school or similar) decreases if too much time is required to supply the knowledge. Gamification addresses this topic by the use of game design elements in non-game contexts (Tan et al. 2011). Gamification provides elements that keep the interest of a person in a specific topic by using design elements like scores, achievements and storylines.

One way to transfer and demonstrate the challenge of sustainable product development is to let people experience this process first hand. Therefore, a "Product Configuration Game" (PCG) was developed in which the user is put in the role of a product developer who has to configure a new product from a limited set of options (Wang et al. 2014). The product in that case is a simplified model of a so called Pedelec (Pedal-Electric Bicycle). The configurable parts of the Pedelec comprise the basic frame and additional functional features. Furthermore, three different suppliers for the basic frame are available. This limited set of configuration options simulates existing supply chains and product politics. All features and product options are assigned with sustainability scores indicating their impact on respective sustainability indicators, such as global warming potential, primary energy consumption or fairness of salary. These scores where derived from results from a LCA conducted by Neugebauer et al. (2013) for a similar use case. By aggregating all sustainability score of one specific setting, a total sustainability 
score is calculated and visualized as bar chart for each of the sustainability dimensions (see Fig. 8). To demonstrate the fact that product developers usually do not have all necessary information about the impact of their choices the visualization of the total sustainability impact is also not available at the beginning of the game. Instead, the users have to rely on vague descriptive characteristics of features, such as material price, weight or design style. Only when they confirmed their decisions the bar charts representing the sustainability impacts are revealed. Then the users can change their decisions to explore the influence of different options. The impacts of their changes are then shown in real time. A further PCG feature, called the "Ontology Browser" allows the user to investigate the complex network of relationships between the product options and the sustainability indicators in a controlled way by using ontological trees developed for this game (Wang et al. 2014).

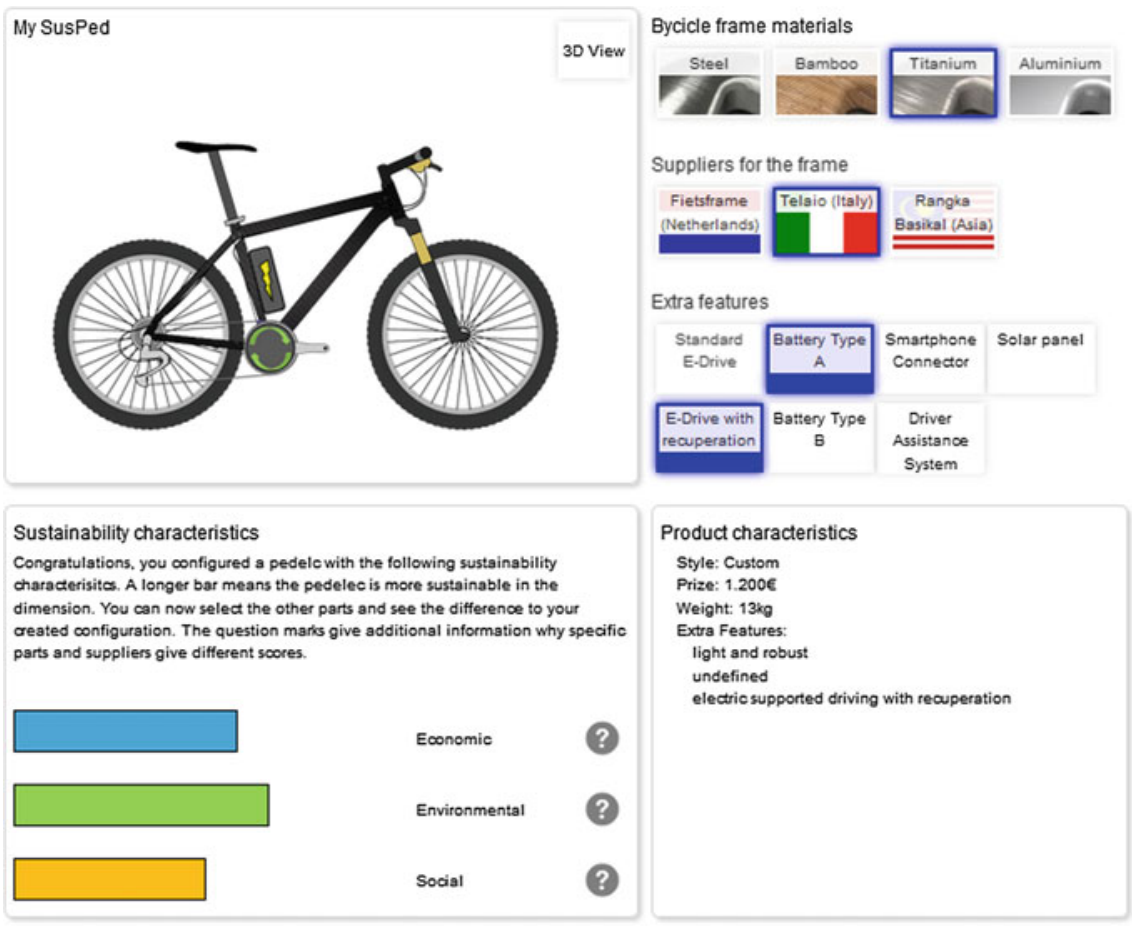

Fig. 8 Product Configuration Game: the user interface provides graphical feedback in the product model and shows impact of configuration decisions on all three sustainability dimensions in real time as bar charts 
Various Gamification Design Elements (Tan et al. 2011) where chosen to motivate the user:

- Mechanics of the configurator construct a system of interacting parts that can be combined to achieve different results, so that exploring the different types of sustainability impact of the pedelec parts is necessary in order to understand the game mechanics

- Feedback visualization shows the result of the combination by delivering not only values in terms of graphs but also by providing a visual of them using a 2D/3D representation of a pedelec, therein enabling one to create her/his own custom-designed bike

- Fun motivator-role-play puts the user into the role of a design engineer with the task of creating a sustainable pedelec

- Fun motivator-research uses the ontological mechanisms for providing a visualization of the complex network behind the sustainability of the pedelec, which then allows the user to explore those networks discovering new relations

Using these gamification elements enriches the configurator in a way that users are kept interested as they are supplied with more information about sustainability during the usage of the configurator.

\section{Conclusion}

If the lifestyles of both economically up-coming and economically developed communities are persist to be shaped by the existing, currently predominant technologies, then resource consumption will exceed every accountable ecological, environmental and social boundary known to man (Seliger 2012; Ueda et al. 2009). However, human initiative and creativity opens up a panoply of paths for future development in pursuit of coping with the challenges of sustainability on a globe scale. Their chances of successful implementation essentially depend on their ability to take hold in an increasingly globalized arena of market driven activities. Both, demand and supply, are thus not only abstract financial figures, but concrete goods in the sense of products and services as artefacts of human activities in manufacturing and design. Manufacturing technology significantly determines how exactly humans create these artefacts, and thus how they shape their environment, communities and individual lives. Directing these human activities to coping with challenges of sustainability is, consequently, a relevant research contribution in manufacturing technology.

In the politically charged arena of sustainable manufacturing with its high economic impact and huge variety of conflicting interest groups, the comparatively neutral position of science can serve to help win over people's trust. At the same time, innovative approaches, methods and tools need to be scientifically developed in order to overcome the educational gap regarding sustainable development and 
even more sustainable manufacturing. The triangle of researching, educating and networking that determines schools' and universities' daily agendas likewise involves the three pillars of ESD science: researching and developing innovative didactic approaches (1), putting them into direct use by integrating them into education as awareness-raising activities (2), and making use of universities' unique localization as experts standing in between politics, industry and a great number of learners in pursuit of building networks for promoting ESD (3).

\section{References}

Ahnert, Liselotte. 2014. Theorien in der Entwicklungspsychologie. Heidelberg: Springer.

Bolscho, Dietmar. 2005. Der Beitrag der Erziehungswissenschaften für die Nachhaltigkeitskommunikation. In Handbuch Nachhaltigkeits-kommunikation, ed. Gerd Michelsen, Jasmin Godemann, 143-150. Munich: Oekom.

Bormann, Inka. 2005. Zwischen Wunsch und Wirklichkeit: Nachhaltigkeitskommunikation in Schulen. In Handbuch Nachhaltigkeits-kommunikation, ed. Gerd Michelsen, Jasmin Godemann, 793-803. Munich: Oekom.

Brand, Karl-Werner. 2005. Nachhaltigkeitskommunikation: eine soziologische Perspektive. In Handbuch Nachhaltigkeitskommunikation, ed. Gerd Michelsen, Jasmin Godemann, 151-161. Munich: Oekom.

Bormann, Inka, Kristina Broens, Felix Brümmer, Bettina Klaczinski, Markus Lindner, Carina Lücke, Sebastian Niedlich, and Sonja Warning. 2015. Evaluation der Kampagne "Schule der Zukunft - Bildung für Nachhaltigkeit”. Düsseldorf: Ministerium für Schule und Weiterbildung des Landes Nordrhein-Westfalen, and Ministerium für Klimaschutz, Umwelt, Landwirtschaft, Natur- und Verbraucherschutz des Landes Nordrhein-Westfalen. http://www.schule-derzukunft.nrw.de/fileadmin/user_upload/Schule-der-Zukunft/Aktuelles/Abschlussbericht_ Evaluation_Schule_der_Zukunft_ENDVERSION.pdf. Accessed 27 Sept 2016.

Chryssolouris, George. 2005. Manufacturing systems: Theory and practice. New York: Springer.

Crawley, Edward F., Johan Malmqvist, Sören Ostlund, and Doris R. Brodeur. 2007. Rethinking engineering education: The CDIO approach. New York: Springer.

Dave, Ravindrakumar H. 1970. Psychomotor levels. In Developing and writing behavioral objectives, ed. Robert J. Armstrong, 33-34. Tucson: Educational Innovators Press.

Fischer, Daniel, and Matthias Barth. 2014. Key competencies for and beyond sustainable consumption. An educational contribution to the debate. GAIA 23(S1): 193-200.

Fiske, Susan T., and Cydney Dupree. 2014. Gaining trust as well as respect in communicating to motivated audiences about science topics. PNAS 111(4): 13593-13597.

Gosling, David, and Jennifer A. Moon. 2001. How to use learning outcomes and assessment criteria. London: SEEC.

Griese, Kai-Michael, Christel Kumbruck, and Christin Michaelis. 2014. Der Einfluss von Humor auf die Nachhaltigkeitskommunikation. Ökologisches Wirtschaften, 29(4): 35-38.

Grunenberg, Heiko, and Udo Kuckartz. 2005. Umweltbewusstsein. Empirische Erkenntnisse und Konsequenzen für die Nachhaltigkeitskommunikation. In Handbuch Nachhaltigkeitskommunikation, ed. Gerd Michelsen, Jasmin Godemann, 195-206. Munich: Oekom.

Harrow, Anita J. 1972. A taxonomy of the psychomotor domain: A guide for developing behavioral objectives. New York: Longman.

Kirkpatrick, Donald. 1996. Great ideas revisited. Techniques for evaluating training programmes: Revisiting Kirkpatrick's four-level model. Training and Development 50(1): 54-59. 
Kolb, David A. 1984. Experiential learning: Experience as the source of learning and development. Englewood Cliffs: Prentice Hall.

Krüger, Jörg, and The Duy Nguyen. 2015. Automated vision-based live ergonomics analysis in assembly operations. CIRP Annals-Manufacturing Technology 64(1): 9-12.

Kruse, Lenelis. 2005. Nachhaltigkeitskommunikation und mehr: die Perspektive der Psychologie. In Handbuch Nachhaltigkeitskommunikation, ed. Gerd Michelsen, and Jasmin Godemann, 109-120. Munich: Oekom.

Lasswell, Harold D. 1948. The structure and function of communication in society. In The communication of ideas: A series of addresses, ed. Lyman Bryson, 32-51. New York: Harper.

Leacock, Tracey L., and John C. Nesbit. 2007. A framework for evaluating the quality of multimedia learning resources. Educational Technology \& Society 10(2): 44-59.

Manufuture High Level Group and Support Group. 2006. Strategic research agenda: Assuring the future of manufacturing in Europe. Brussels: ManuFuture Platform. https://www.um.es/ operum/plataformas/files/manufuture.pdf. Accessed 27 Sept 2016.

Mattes, Wolfgang. 2011. Methoden für den Unterricht: Kompakte Übersichten für Lehrende und Lernende. Paderborn: Schöningh.

Mayer, Horst Otto, Johannes Hertnagel, and Heidi Weber. 2009. Lernzielüberprüfung im eLearning. München: Oldenbourg.

McFarland, Randy, Carsten Reise, Alexandra Postawa, and Günther Seliger. 2013. Learnstruments in value creation and learning centered work place design. In Proceedings of the 11th global conference on sustainable manufacturing - innovative solutions, ed. Günther Seliger, 624-629. Berlin: Universitätsverlag der TU Berlin.

Michelsen, Gerd. 2005. Nachhaltigkeitskommunikation: Verständnis - Entwicklung Perspektiven. In Handbuch Nachhaltigkeitskommunikation, edited by Gerd Michelsen, Jasmin Godemann, 25-41. Munich: Oekom.

Muschard, Bernd, and Günther Seliger. 2015. Realization of a learning environment to promote sustainable value creation in areas with insufficient infrastructure. Procedia CIRP 32: 70-75.

Neugebauer, Sabrina, Ya-Ju Chang, Markus Maliszewski, Kai Lindow, Rainer Stark, and Matthias Finkbeiner. 2013. Life cycle sustainability assessment \& sustainable product development: A case study on pedal electric cycles (Pedelec). In Proceedings of the 11th global conference on sustainable manufacturing - innovative solutions, ed. Günther Seliger, 549-554. Berlin: Universitätsverlag der TU Berlin.

Pappas, Eric, Olga Pierrakos, and Robert L. Nagel. 2013. Using Bloom's taxonomy to teach sustainability in multiple contexts. Journal of Cleaner Production 48: 54-64.

Reeves, Phil. 2012. Democratizing Manufacturing: 3D Printing in the Developing World. Yumpu. https://www.yumpu.com/en/document/view/46578172/democratizing-manufacturingeconolyst/1. Accessed 27 Sept 2016.

Roeder, Ina, Matthias Scheibleger, and Rainer Stark. 2015. How to make people make a change: Using social labelling for raising awareness on sustainable manufacturing. Procedia CIRP 40: 359-364.

Roeder, Ina, Mustafa Severengiz, Rainer Stark, and Günther Seliger. 2016. Open educational resources as driver for manufacturing-related education for learning of sustainable development. Paper to be presented at 14th Global Conference on Sustainable Manufacturing, Stellenbosch, South Africa, October 3-5, 2016.

Simpson, Elizabeth J. 1972. The classification of educational objectives in the psychomotor domain. Urbana: Gryphon House.

Seliger, Günther. 2012. Sustainable manufacturing for global value creation. In Sustainable manufacturing: Shaping global value creation, ed. Günther Seliger, 3-8. Berlin: Springer.

Seliger, Günther, Carsten Reise, and Rand McFarland. 2009. Outcome-oriented learning environment for sustainable engineering education. In Proceedings of the 7th global conference on sustainable manufacturing-sustainable product development and life cycle engineering, ed. Günther Seliger, 91-98. Berlin: Universitätsverlag der TU Berlin.

Tan, D., S. Amershi, B. Begole, W.A. Kellogg, M. Tungare, S. Deterding, et al. 2011. Gamification using game-design elements in non-gaming contexts. In Proceedings of the 2011 
annual conference extended abstracts on Human factors in computing systems, ed. D. Tan, 2425-2428. New York, NY: ACM.

Ueda, Kanji, Takeshi Takenaka, Jozsef Váncza, and László Monostori. 2009. Value creation and decision-making in sustainable society. CIRP Annals — Manufacturing Technology 58(2): 681-700.

UNESCO. 2012. 2012 World Open Educational Resources Congress: Wednesday 20-Friday 22 June, 2012. http://www.unesco.org/new/fileadmin/MULTIMEDIA/HQ/CI/CI/pdf/CI_Information_ Meetings/2012_world_oer_congress_en.pdf. Accessed 27 Sept 2016.

Wals, Arjen E.J. 2015. Social learning-oriented capacity-building for critical transitions towards sustainability. In Schooling for sustainable development in Europe: Concepts, policies and educational experiences at the end of the UN decade of education for sustainable development, ed. Rolf Jucker, and Reiner Mathar, 87-107. Cham: Springer.

Wang, Wei M., Lars Wolter, Kai Lindow, and Rainer Stark. 2014. Graphical visualization of sustainable manufacturing aspects for knowledge transfer to public audience. Procedia CIRP 26: 58-63.

Weintraub Austin, Erica, and Bruce E. Pinkleton. 2015. Strategic public relations management: Planning and managing effective communication programs. New York: Routledge.

Zirfas, Jörg, and Michael Göhlich. 2007. Lernen: Ein pädagogischer Grundbegriff. Stuttgart: Kohlhammer.

Open Access This chapter is licensed under the terms of the Creative Commons Attribution 4.0 International License (http://creativecommons.org/licenses/by/4.0/), which permits use, sharing, adaptation, distribution and reproduction in any medium or format, as long as you give appropriate credit to the original author(s) and the source, provide a link to the Creative Commons license and indicate if changes were made.

The images or other third party material in this chapter are included in the book's Creative Commons license, unless indicated otherwise in a credit line to the material. If material is not included in the book's Creative Commons license and your intended use is not permitted by statutory regulation or exceeds the permitted use, you will need to obtain permission directly from the copyright holder.

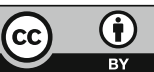

